\title{
CARACTERIZACIÓN DE BACTERIAS HALOTOLERANTES AISLADAS DEL PROCESO DE SALADO-MADURADO DE Engraulis ringens (Jenyns, 1842) "ANCHOVETA"
}

\section{CHARACTERIZATION OF HALOTOLERANT BACTERIA ISOLATED FROM THE MATURE-SALTED PROCESS OF Engraulis ringens (Jenyns, 1842) "ANCHOVETA"}

\author{
Roxana Céspedes-Chombo ${ }^{1,2,3}$, Amparo Iris Zavaleta ${ }^{3}$, Susana Calderón-Toledo ${ }^{3,4}$, Cynthia \\ Esquerre-Huallpa ${ }^{3}$ y Miguel Albrecht-Ruiz ${ }^{1}$
}

\begin{abstract}
Resumen
El objetivo de esta investigación fue caracterizar bacterias halotolerantes aisladas del proceso de salado-madurado de Engraulis ringens provenientes de una empresa pesquera de Chimbote (Perú). Para ello, se recolectaron tres muestras de pescado al inicio y término del proceso. Se aislaron 14 bacterias halotolerantes, 12 aisladas en medio con $\mathrm{NaCl}$ al 5\% y dos al $10 \%$. Se evaluó su capacidad de crecimiento a temperaturas de 4 a $50{ }^{\circ} \mathrm{C}$ y de 2.5 a $12.5 \%$ de $\mathrm{NaCl}$, así como su actividad bioquímica con las pruebas de oxidasa, ureasa, indol, utilización de citrato, fermentación de carbohidratos, hidrólisis de almidón, caseína y gelatina, y su sensibilidad a penicilina, cloranfenicol, gentamicina, tetraciclina, rifampicina, sulfametoxazol/trimetoprima, estreptomicina, ácido nalidíxico y novobiocina. $\mathrm{El} 71 \%$ de las cepas creció entre 25 y $44{ }^{\circ} \mathrm{C}$ y hasta $10 \%$ de $\mathrm{NaCl}$, y presentaron actividad proteolítica y amilolítica. La caracterización molecular se realizó amplificando los genes ribosómicos $16 \mathrm{~S}$, los que se secuenciaron y analizaron mediante los programas BioEdit y BLASTn. De esta caracterización se obtuvieron los géneros Bacillus (2), Staphylococcus (6), Oceanobacillus (1), Salinococcus (1), Psychrobacter (2) y Sporosarcina (2). Cinco géneros de bacterias halotolerantes aisladas (Bacillus, Oceanobacillus, Salinicoccus, Psychrobacter y Sporosarcina) fueron de procedencia marina y no patógenas ni indicadoras de contaminación. Al contrario, se identificaron cepas del género Staphylococcus, como BH1 que presentó sensibilidad solo al ácido nalidíxico, mientras que BH14 fue resistente a todos los antimicrobianos. Por lo tanto, es necesario implementar medidas que garanticen la inocuidad de las anchoas.
\end{abstract}

Palabras clave: Engraulis ringens, anchoas, bacterias halotolerantes, sensibilidad microbiana, Staphylococcus.

\begin{abstract}
The objective of this research was to characterize halotolerant bacteria isolated from the ripened salty process of Engraulis ringens from a fishing company at Chimbote (Peru). For this, three fish samples were collected at the beginning and at the end of the process. 14 halotolerant bacteria were isolated, 12 from medium containing $5 \% \mathrm{NaCl}$ and two from $10 \% \mathrm{NaCl}$. Its growth capacity was evaluated from 4 to $50^{\circ} \mathrm{C}$ and 2.5 to $12.5 \% \mathrm{NaCl}$, as well as its biochemical activity by oxidase, urease, indole and citrate tests, carbohydrate fermentation, hydrolysis of starch, casein and gelatin, and sensitivity to penicillin, chloramphenicol, gentamicin, tetracycline, rifampicin, sulfamethoxazole/trimethoprim, streptomycin, nalidixic acid, and novobiocin. $71 \%$ of strains grew from 25 to $44{ }^{\circ} \mathrm{C}$, up to $10 \% \mathrm{NaCl}$, and showed proteolytic and amylolytic activities. The molecular characterization was carried out by amplification and sequencing the $16 \mathrm{~S}$ ribosomal genes and these were analyzed using BioEdit and BLASTn programs. From this characterization, the genera Bacillus (2), Staphylococcus (6), Oceanobacillus (1), Salinococcus (1), Psychrobacter (2) and Sporosarcina (2) were obtained. Five genera of isolated halotolerant bacteria (Bacillus, Oceanobacillus, Salinicoccus, Psychrobacter and Sporosarcina) were of marine origin, they are non-pathogenic or no pollution indicators. Conversely, BH1 strain of Staphylococcus showed sensitivity only to nalidixic acid, while BH14 was resistant to all antimicrobials. Therefore, it is necessary to implement measures that ensure the safety of anchovies.
\end{abstract}

Key words: Engraulis ringens, anchovies, halotolerant bacteria, microbial sensitivity, Staphylococcus.

\section{Introducción}

La maduración de anchoas en salazón es una actividad tradicional en países mediterráneos, la cual utiliza a Engraulis encrasicolus (boquerón europeo) como insumo. En las últimas décadas, la captura de esta especie disminuyó por la sobrepesca y el cambio 
climático, por lo que fue reemplazada por E. anchoita y E. ringens (MAGRAMA, 2017).

En Perú, Engraulis ringens es la principal especie exportada debido a su buena adaptación, con utilidad en la producción de harina y aceite de pescado (Bouchon et al., 2010); sin embargo, la producción de "anchoas" se ha incrementado en la última década, comercializándola en barriles o como semiconservas. Así, su elaboración tradicional se inicia con el eviscerado del pescado fresco para, después, ser colocado en barriles, alternando capas de pescado y sal, en proporción de 4:1, y ser madurado de 4 a 8 meses.

La calidad se determina por condiciones biológicas intrínsecas del espécimen, tales como tamaño y contenido graso; sin embargo, son determinantes la manipulación del pescado después de su captura y la exposición a temperaturas inadecuadas, por el potencial riesgo de contaminación microbiológico o por histamina, previo al proceso de maduración (Zugarramurdi et al., 2004).

En consecuencia, durante la maduración de las anchoas, se han reportado diferentes poblaciones microbianas con requerimientos salinos obligatorios y facultativos, entre ellas bacterias ácido lácticas, enterobacterias, estafilococos y levaduras, que afectan las características organolépticas y la seguridad alimentaria del producto final (Czerner et al., 2011; Verdos et al., 2018). En esta investigación, se caracterizaron bacterias halotolerantes aisladas del proceso de maduración de anchoveta en salazón, utilizando métodos bacteriológicos y moleculares, con el fin de estimar la calidad microbiológica del producto y aportar sobre su seguridad alimentaria.

\section{Materiales y métodos}

\section{Recolección de muestras}

Se recolectaron 12 muestras, seis al inicio (marzo) y seis al término (octubre) de un mismo lote del año 2017, del proceso de salado-madurado de la anchoveta (Engraulis ringens) proveniente de una empresa pesquera de Chimbote (Perú), las cuales se transportaron en recipientes a $4{ }^{\circ} \mathrm{C}$ hasta su análisis antes de las $24 \mathrm{~h}$.

Recuento y aislamiento

Los métodos utilizados fueron los descritos por Kim et al. (2015). Para el homogenizado de la muestra se utilizó $50 \mathrm{~g}$ de muestra con $450 \mathrm{ml}$ de agua peptonada $(0.5 \%$ de peptona y $\mathrm{NaCl}$ al $3 \%(\mathrm{p} / \mathrm{v}))$. Se realizó la siembra para el recuento en placas conteniendo agar tripticasa de soya con 5 y $10 \%$ de $\mathrm{NaCl}$ (w/v) incubadas a $25^{\circ} \mathrm{C}$ por 4 días.

Para el aislamiento bacteriano se seleccionaron las colonias morfológicamente diferentes de los muestreos al inicio de la maduración en marzo y a su término en octubre, las que se sembraron en agar tripticasa de soya mediante las condiciones anteriormente mencionadas. A las cepas aisladas se les realizaron las pruebas fisiológicas, análisis bioquímicos, sensibilidad antimicrobiana y caracterización molecular.

\section{Pruebas fisiológicas}

La capacidad de crecimiento de las bacterias a concentraciones de $2.5,5,7.5,10$ y $12.5 \%$ de $\mathrm{NaCl}$ se realizó en caldo agua de sales suplementado con extracto de levadura al $0.5 \%$. La tolerancia a diferentes temperaturas se determinó en agar tripticasa de soya a $4,25,35,44$ y $50{ }^{\circ} \mathrm{C}$ por uno a cuatro días.

\section{Pruebas bioquímicas}

Se realizaron en medios sólidos y líquidos conteniendo $\mathrm{NaCl}$ al 5\% (w/v) las pruebas de presencia de oxidasa y ureasa, producción de indol, utilización de citrato y fermentación de carbohidratos (glucosa, sacarosa, salicina y lactosa).

Hidrólisis de sustratos

Se realizaron en medios sólidos conteniendo $\mathrm{NaCl}$ al 5\%. Se determinó la hidrólisis del almidón con la observación de halos claros alrededor del crecimiento bacteriano después de añadir solución de yodo. La hidrólisis de caseína y gelatina en placa se observó por la aparición de un halo transparente alrededor del crecimiento bacteriano.

$\underline{\text { Sensibilidad microbiana }}$

Como medio base se usó agar Müeller-Hinton conteniendo $5 \%$ de $\mathrm{NaCl}$, se inoculó $0.1 \mathrm{ml}$ de la bacteria a una $\mathrm{OD}_{550}=0.5$. Después, se colocaron los discos de los antimicrobianos, según el método descrito por Rani et al. (2017). Los antimicrobianos utilizados fueron: penicilina $10 \mathrm{U} / \mathrm{IE}$, cloranfenicol $30 \mu \mathrm{g}$, gentamicina $10 \mu \mathrm{g}$, tetraciclina $30 \mu \mathrm{g}$, rifampicina $5 \mu \mathrm{g}$, sulfametoxazol/trimetoprima $25 \mu \mathrm{g}$, estreptomicina $10 \mu \mathrm{g}$, ácido nalidíxico $30 \mu \mathrm{g}$, novobiocina $5 \mu \mathrm{g}$. Las placas se incubaron a $35^{\circ} \mathrm{C}$ por $24 \mathrm{~h}$. Luego se realizó la lectura de los halos de inhibición y se correlacionó con la concentración mínima inhibitoria (CMI).

Caracterización molecular

La extracción de ADN genómico se realizó por medio del método de solventes orgánicos (Canales et al., 2014). Los genes ribosómicos $16 \mathrm{~S}$ se amplificaron mediante la reacción en cadena de la polimerasa utilizando los cebadores 16SF:5' AGAGTTTGATCATGGCTCAG-3', 16SR:5' GGTTACCTTGTTACGACTT-3'. El volumen de reacción $(25 \mu \mathrm{l})$ contenía: $\mathrm{KCl} 50 \mathrm{mM}$, Tris/ $\mathrm{HCl} 10$ $\mathrm{mM}$, tritón X-100 0.1\% (v/v), $\mathrm{MgCl}_{2} 1.5 \mathrm{mM}$, dNTPs $200 \mu \mathrm{M}$, cebadores 20 pmoles de c/u, Taq ADNpolimerasa $1 \mathrm{U}$ y ADN $50 \mathrm{ng}$. Los genes amplificados fueron separados por electroforesis en gel de agarosa $1 \%$ con buffer TBE 1X. Después, fueron secuenciados utilizando los cebadores antes mencionados, así como 1100R:5'-AGGGTTGCGCTCGTTG-3'. Para su análisis, se utilizaron los programas BioEdit para alinear las secuencias y BLASTn para buscar similitud con las secuencias de GenBank mediante el algoritmo BLAST. 


\section{Resultados y discusión}

$\underline{\text { Recuento y aislamiento de bacterias halotolerantes }}$

Las muestras fueron analizadas mediante el método APHA para bacterias halotolerantes y los recuentos se expresaron en Unidades Formadoras de Colonias (UFC/g). Así, a mayor tiempo de maduración de las anchoas, el recuento de bacterias halotolerantes se incrementó en el medio conteniendo $\mathrm{NaCl}$ al 5\% (Tabla 1), mientras que al $10 \%$ el número fue menor. Según Czerner \& Yeannes (2014), durante la primera semana del madurado se produce una pérdida de agua cercana al 25\%, así como un aumento del contenido de sal de 15 a $20 \%$ y una disminución del pH entre 5.60 a 5.75 . Los autores sostienen que estos valores fisicoquímicos permanecen constantes hasta el final del proceso y que favorecen el crecimiento de bacterias halotolerantes y halófilas. Además, durante el madurado, las bacterias halófilas moderadas y extremas se adaptan gradualmente al medio a medida que se incrementa la disponibilidad de nutrientes debido a procesos proteolíticos de las anchoas. Este proceso adaptativo puede explicar el aumento de 220 a 920 UFC/g observado en los medios de cultivo conteniendo $\mathrm{NaCl}$ al 5\%. Los recuentos de bacterias halotolerantes provenientes de muestras de ambos barriles obtenidos al final del proceso fueron menores a $10^{5} \mathrm{UFC} / \mathrm{g}$ que, según Gram \& Huss (1996), podrían impartir olores desagradables, dependiendo de la biota.

Tabla 1. Recuento de bacterias halotolerantes del proceso de salado-madurado de anchovetas provenientes de Chimbote, año 2017.

\begin{tabular}{|c|c|c|c|c|}
\hline \multirow{3}{*}{$\mathbf{N}^{0}$ Barril } & \multirow{2}{*}{\multicolumn{4}{|c|}{$\begin{array}{c}\text { marzo } \\
\text { Recuento de bacterias halotolerantes } \\
\text { (UFC/g) }\end{array}$}} \\
\hline & & & & \\
\hline & A & B & $\mathbf{A}$ & B \\
\hline 1 & 220 & 28 & 920 & 72 \\
\hline 2 & 360 & 31 & 970 & 85 \\
\hline
\end{tabular}

$\mathrm{B}, \mathrm{NaCl} 10 \%$.

La selección de las bacterias aisladas de las muestras de anchoas en salazón fue realizada bajo el criterio de diferencias morfológicas de las colonias. En consecuencia, se seleccionaron 14 bacterias halotolerantes $(\mathrm{BH})$, de las cuales 12 (BH1, BH2, BH6, $\mathrm{BH} 11, \mathrm{BH} 12, \mathrm{BH} 12.2, \mathrm{BH} 14, \mathrm{BH} 16, \mathrm{BH} 17, \mathrm{BH} 18$, BH19 y BH20) fueron aisladas del medio conteniendo $5 \%$ de $\mathrm{NaCl}$, y dos cepas (BHE11 y BHE12) fueron aisladas del medio con $10 \%$ de $\mathrm{NaCl}$. Así, las 14 cepas seleccionadas fueron purificadas mediante pasajes sucesivos y sujetas a tinción Gram, pruebas bioquímicas y tolerancia salina y térmica.

Pruebas fenotípicas y bioquímicas

Las bacterias seleccionadas mostraron diferente morfología celular. Entre estas, nueve fueron cocos Gram positivos, tres bacilos Gram positivos y dos cocos Gram negativos. Las colonias predominantes fueron de color crema, con forma circular, con borde definido y con superficie lisa. Además, algunos aislados formaron colonias con bordes irregulares. Las pruebas de oxidasa, ureasa, indol, citrato y fermentación de carbohidratos mostraron perfiles variables (Tabla 2). Ninguna de las cepas aisladas requirió $\mathrm{NaCl}$ para crecer, sin embargo, tuvieron tolerancia salina entre 10.0 a $12.5 \%$ (Figura 1). Entre estas, 11 cepas crecieron en un amplio rango de salinidad de entre 0 y $10 \%$, y tres mostraron halotolerancia hasta $12.5 \%$. Además, las cepas BH6 y BH16 crecieron entre 25 a $50{ }^{\circ} \mathrm{C}$ y BHE11 creció entre 4 y $44{ }^{\circ} \mathrm{C}$.

De las bacterias aisladas, el grupo dominante fue el de los cocos Gram positivos, halotolerantes (64\%). Estos hallazgos están en concordancia con lo descrito por Pons et al. (2005), quienes reportaron que la población de cocos Gram positivos permaneció constante, alcanzando $10^{3} \mathrm{UFC} / \mathrm{g}$ durante el proceso de salado-madurado de E. encrasicolus. Por el contrario, el recuento bacteriano en medio con $10 \%$ de $\mathrm{NaCl}$ fue menor.

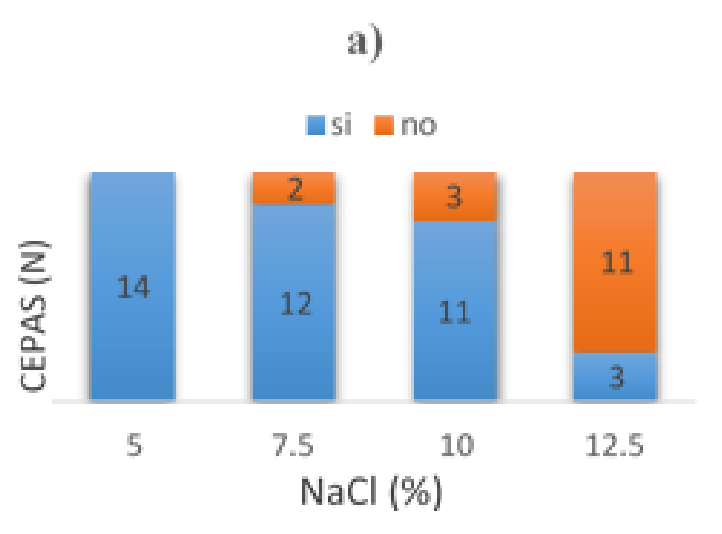

b)

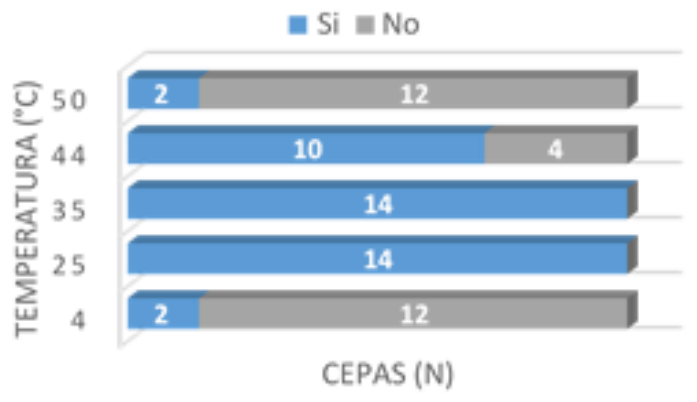

Figura 1. Tolerancia salina (a) y térmica (b) de bacterias halotolerantes aisladas del proceso de salado-madurado de anchovetas provenientes de Chimbote / Perú.

Por otro lado, la actividad enzimática microbiana sobre las fracciones lipídicas y proteicas del pescado contribuyen al desarrollo de las características sensoriales de las anchoas. Por ejemplo, la lipólisis 
libera ácidos grasos libres susceptibles a oxidación cuyos productos contribuyen al aroma de las anchoas, mientras que las enzimas proteolíticas generan péptidos y aminoácidos, responsables de la textura característica del producto madurado. Por lo tanto, las actividades lipolítica y proteolítica dependen de la microbiota de las anchoas, la cual influye en las características bioquímicas deseables para el madurado. Sin embargo, las bacterias formadoras de indol están relacionadas con la producción de sabores desagradables; este caso se presentó en 11 bacterias aisladas (Tabla 2). El 57\% (8) de las cepas fueron proteolíticas, específicamente siete cocos y un bacilo, ambos Gram positivos. En este aspecto, Czerner \& Yeannes (2014) reportaron que las bacterias proteolíticas fueron el $5 \%$ del total de bacterias aisladas durante el proceso de madurado de E. anchoita. Asimismo, Perez et al. (2018) estudiaron las comunidades microbianas de halófilos del madurado de E. anchoita y determinaron que el $25 \%$ eran proteolíticas.

La formación de indol es una característica bioquímica indeseable de la biota del proceso de salado-madurado de anchoas debido a que este compuesto podría impartir sabor y olores desagradables al producto (Perez et al., 2020). Las pruebas bacteriológicas evidenciaron que esta actividad enzimática fue compartida por el $78 \%$ de bacterias aisladas. Sin embargo, no se puede determinar si esta actividad es favorecida bajo las condiciones fisicoquímicas existentes en el proceso productivo. Además, nueve aislados hidrolizaron almidón, de los cuales seis fueron cocos Gram positivos, dos cocos Gram negativos y un bacilo Gram positivo.

En la caracterización bioquímica de las bacterias halotolerantes aisladas, estas mostraron perfiles hidrolíticos y acidificación de azúcares variados y disimiles entre sí, lo cual fue descrito previamente por Tanasupawat et al. (2010), quienes reportaron bacterias halotolerantes y halófilas moderadas en salsa de pescado tailandés ("pla-ra"), donde reconocieron seis grupos taxonómicos con mayor presencia de bacilos Gram positivos de características variables en la acidificación de azúcares.

Sensibilidad antimicrobiana

Con respecto a las pruebas antimicrobianas se determinaron ocho perfiles de sensibilidad. La cepa $\mathrm{BH} 14$ fue resistente a todos los antimicrobianos y BH1 sensible solo a ácido nalidíxico. Al contrario, las cepas BH12.2 y BH17 fueron sensibles (Tabla 3). Asimismo, en la Figura 2 se observa que 13 cepas presentaron sensibilidad al ácido nalidíxico, así como alta tasa de resistencia a novobiocina. Por tanto, a pesar de la similitud de características morfológicas, existen diferencias excepcionales que brindan al agente antimicrobiano capacidad de inhibir el crecimiento. De igual forma, Elyasifar et al. (2019), al identificar bacterias halófilas entre Bacillus, Halobacillus y Virgibacillus, señalaron baja sensibilidad a gentamicina y resistencia a rifampicina y tetraciclina, como se obtuvo para las cepas BH1, BH6, BH12, BH14, BH19 y BH20, que indican multirresistencia. Por otro lado, Puig et al. (2019) determinaron un patrón de multirresistencia para cloranfenicol, eritromicina y tetraciclina de Staphylococcus aislado de pescado, comprometiendo pérdidas en la producción y seguridad alimentaria.

Tabla 3. Perfiles de sensibilidad de bacterias halotolerantes aisladas del proceso de salado-madurado de anchovetas provenientes de Chimbote.

\begin{tabular}{lll}
\hline Perfil & Antimicrobianos & Cepa sensible* \\
\hline I & NAL & BH1 \\
II & SMX-TMP, STR, NAL & BH6 \\
III & CLOR, SMX-TMP, NAL & BH19, BH20, BHE12 \\
IV & CLOR, TET, RIF, SMX- & BHE11, BH11
\end{tabular}

V CLOR, TET, RIF, SMX- BH12, BH18

VI CLOR, TET, SMX- BH2

TMP, NAL, STR, NOV

VII PEN, CLOR, TET, RIF, BH 16 SMX-TMP, STR, NAL, NOV

VIII PEN, CLOR, GEN, TET, BH12.2, BH 17 RIF, SMX-TMP, STR, NAL, NOV

PEN: penicilina, CLOR: cloranfenicol, GEN: gentamicina, TET: tetraciclina, RIF: rifampicina, SMX-TMP: sulfametoxazol/trimetoprima, STR: estreptomicina, NAL: ácido nalidíxico, NOV: novobiocina.

*, cepa BH14 fue resistente a todos los antimicrobianos analizados.

\section{Caracterización molecular}

El análisis de las secuencias parciales de los genes ribosómicos $16 \mathrm{~S}$ indicó la presencia de los géneros Staphylococcus, Salinicoccus, Psychrobacter, Bacillus, Oceanobacillus y Sporosarcina (Tabla 4). Estudios relacionados con el género Sporosarcina indican que la mayoría de especies han sido aisladas de mares o ambientes. Así, presentan un rango óptimo de crecimiento entre 20 a $30{ }^{\circ} \mathrm{C}$ y salinidad $(<15 \%$ de $\mathrm{NaCl}$ ) acorde con las características de las cepas BHE12 y BH18 (The Editorial Board, 2015). Por otro lado, Oceanobacillus comprende 24 especies y tolera $\mathrm{NaCl}$ hasta $21 \%$, con crecimiento óptimo entre 6 a $8 \%$, acorde con BH11 (Liu \& Yang, 2014). Salinicoccus, otro género identificado, presenta cerca de 70 genes asociados a la osmorregulación, con una salinidad óptima del 10\%, similar a BHE11 (Yi-Guang et al., 2008; Hyun et al., 2013). Psycrobacter ha sido aislado de diversos ecosistemas donde algunos pueden tolerar hasta $12 \%$ de $\mathrm{NaCl}$ y $40{ }^{\circ} \mathrm{C}$, lo cual estuvo dentro del rango de crecimiento para las cepas BH17 y BH12.2 (Romanenko et al., 2004). Otro género fue Staphylococcus, caracterizado por su alta adaptabilidad a bajas temperaturas debido al engrosamiento de su pared, así como halotolerancia. Esto se debe a que aproximadamente 90 genes regulan el estrés salino con 
mecanismos entre engrosamiento de su pared y prolina como osmoprotector (Onyango \& Alreshidi, 2018; Das et al., 2020). Estos datos explican el comportamiento de las cepas BH1, BH6, BH12, BH14, BH19 у BH20, que presentaron diferentes perfiles de adaptabilidad a bajas temperaturas y salinidad. No obstante, las cepas BH2 y BH16 identificadas como Bacillus sp. demostraron tolerancia a $50{ }^{\circ} \mathrm{C}$ ligada a una mayor esporulación como mecanismo de adaptabilidad de este género (Carlin et al., 2010).

Tabla 4. Porcentaje de similitud de la secuencia parcial de los genes ribosómicos $16 \mathrm{~S}$ de bacterias halotolerantes aisladas del proceso de salado-madurado de anchovetas provenientes de Chimbote.

\begin{tabular}{llc}
\hline Cepa & Género & Similitud (\%) \\
\hline BH1 & Staphylococcus & 98 \\
BH2 & Bacillus & 99 \\
BH6 & Staphylococcus & 99 \\
BH11 & Oceanobacillus & 98 \\
BHE11 & Salinicoccus & 99 \\
BH12 & Staphylococcus & 97 \\
BH12.2 & Psychrobacter & 98 \\
BHE12 & Sporosarcina & 98 \\
BH14 & Staphylococcus & 99 \\
BH16 & Bacillus & 99 \\
BH17 & Psychrobacter & 99 \\
BH18 & Sporosarcina & 99 \\
BH19* & Staphylococcus & 94 \\
BH20* & Staphylococcus & 98 \\
\hline
\end{tabular}

*, cepas bacterianas aisladas al término de la maduración, las restantes a su inicio.

Por tanto, la presencia de cepas de Staphyloccus multirresistentes indica la adaptabilidad metabólica, así como la necesidad de no solo controlar el proceso de salado-madurado, sino adoptar nuevas medidas de control antes de su comercialización. Finalmente, la NTP 204.056:2006 (revisada el 2013) para anchoas en salazón y envasadas (INDECOPI, 2013) y la Resolución de SANIPES N 057-2016-SANIPES-DE (SANIPES, 2016) señalan el control de diversos microorganismos, entre mesófilos y hongos; sin embargo, no contemplan los parámetros permisibles para bacterias halotolerantes, siendo estas importantes por su impacto en la inocuidad alimentaria. Tal es el caso del género Staphylococcus, el cual estuvo presente al inicio y término del proceso de salado-madurado de las anchoas. Al respecto, Huss (1997) indica que el pescado puede ser contaminado con Staphylococcus a través de manipuladores, utensilios o a partir del ambiente de trabajo. Por ello, es importante considerar el estudio de las bacterias halotolerantes durante el proceso de salazón de las anchoas.

\section{Conclusiones}

Del proceso de salado-madurado de anchovetas provenientes de una empresa de anchoas de Chimbote
/ Perú, se aislaron 14 bacterias halotolerantes; estas fueron agrupadas en los géneros Bacillus (2), Staphylococcus (6), Salinococcus (1), Oceanobacillus (1), Psychrobacter (2) y Sporosarcina (2). La mayoría de bacterias presentaron diferentes actividades enzimáticas, así como tolerancia salina hasta $10 \%$ y térmica hasta $44{ }^{\circ} \mathrm{C}$.

Los géneros bacterianos identificados, a excepción de Staphylococcus, tienen como hábitats ambientes marinos, no son patógenas y no son indicadores de contaminación, según la regulación de la Comunidad Europea y el FDA.

Las cepas de Staphylococcus aisladas presentaron multirresistencia, por lo cual es necesario adoptar medidas de control en el proceso de salado-madurado del pescado.

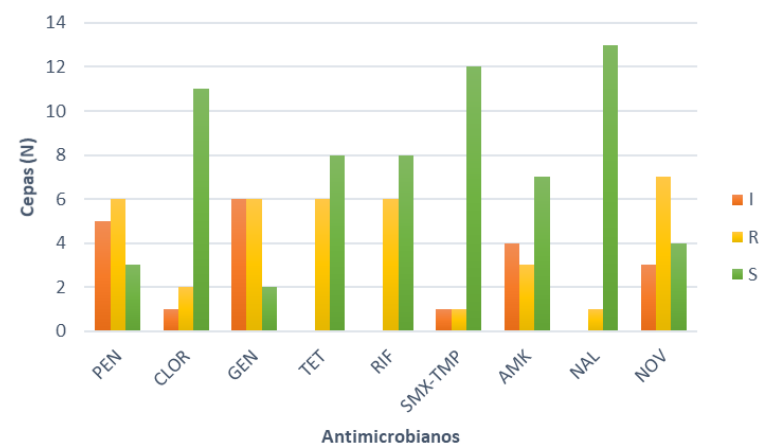

PEN: penicilina, CLOR: cloranfenicol, GEN: gentamicina, TET: tetraciclina, RIF: rifampicina, SMX-TMP: sulfametoxazol/trimetoprima; STR: estreptomicina, NAL: ácido nalidíxico, NOV: novobiocina. Diámetro del halo S: 21 $-34 \mathrm{~mm}$, I: $17-20 \mathrm{~mm}$, R: $6-16 \mathrm{~mm}$.

Figura 2. Recuento de bacterias halotolerantes, con sensibilidad antimicrobiana, aisladas del proceso de salado-madurado de anchovetas procedentes de Chimbote / Perú.

\section{Agradecimientos}

A FONDECYT-CONCYTEC por el financiamiento otorgado.

\section{Literatura citada}

Bouchon M., Mori J., Peña C., Espinoza P., Hutchings L., Buitrón N., Perea A., Goicochea C. \& Messie M. 2010. Biología de la anchoveta peruana, Engraulis ringens Jenyns. Boletín IMARPE, 25(1-2): 23-30. http://biblioimarpe.imarpe.gob.pe/handle/123456789/10 99.

Canales P.E., Chávez-Hidalgo E.L. \& Zavaleta A.I. 2014. Caracterización de bacterias halófilas productoras de amilasas aisladas de las Salinas de San Blas en Junín. Revista Colombiana de Biotecnología, 16(2): 150-157. DOI: $10.15446 /$ rev.colomb.biote.v16n2.43763. 
Carlin F., Brillard J., Broussolle V., Clavel T., Duport C., Jobin M., Guinebretière M., Auger S., Sorokine A. \& Nguyen-Thé C. 2010. Adaptation of Bacillus cereus, an ubiquitous worldwide-distributed foodborne pathogen, to a changing environment. Food Research International, 43(7): 1885-1894. DOI: 10.1016/j.foodres.2009.10.024.

Czerner M. \& Yeannes M.I. 2014. Bacterial contribution to salted anchovy (Engraulis anchoita Hubbs and Marinni, 1935) ripening process. J. Aquat. Food Prod. Technol., 23(2): 102-114. DOI: 10.1080/10498850.2012.697537.

Czerner M., Tomás M.C. \& Yeannes M.I. 2011. Ripening of salted anchovy (Engraulis anchoita): development of lipid oxidation, colour and other sensorial characteristics. J. Sci. Food Agric., 91(4): 609-615. DOI: $10.1002 /$ jsfa.4221.

Das P., Behera B., Chatterjee S., Das B.K. \& Mohapatra T. 2020. De novo transcriptome analysis of halotolerant bacterium Staphylococcus sp. strain P-TSB-70 isolated from East coast of India: In search of salt stress tolerant genes. PLOS ONE, 15: 1-28.

DOI: 10.1371/journal.pone.0228199.

Elyasifar B., Jafari S., Hallaj-Nezhadi S., Chapeland-Leclerc F., Ruprich-Robert G. \& Dilmaghani A. 2019. Isolation and Identification of Antibiotic-Producing Halophilic Bacteria from Dagh Biarjmand and Haj Aligholi Salt Deserts, Iran. Pharmaceutical Sciences, 25(1): 70-77. DOI: $10.15171 /$ PS.2019.11.

Gram L. \& Huss H.H. 1996. Microbiological spoilage of fish and fish products. International Journal of Food Microbiology, 33(1): 121-137. DOI: $10.1016 / 0168-1605(96) 01134-8$.

Huss H.H. 1997. Aseguramiento de la calidad de los productos pesqueros. Documento Técnico de Pesca $\mathrm{N}^{\circ}$ 334. Food and Agriculture Organization (FAO). Roma. http://www.fao.org/3/t1768s/T1768S00.htm\#TOC.

Hyun D.W., Whon T.W., Cho Y.J., Chun J., Kim M., Jung M., Shin N., Kim J., Kim P., Yun J., Lee J., Oh S.J. \& Bae J. 2013. Genome sequence of the moderately halophilic bacterium Salinicoccus carnicancri type strain $\mathrm{Crm}(\mathrm{T})(=$ DSM 23852(T)). Standards in genomic sciences, 8(2): 255-263. DOI: 10.4056/sigs.3967649.

INDECOPI. 2013. RESOLUCIÓN COMISIÓN DE NORMALIZACIÓN Y DE FISCALIZACIÓN DE BARRERAS COMERCIALES NO ARANCELARIAS $\mathrm{N}^{\circ}$ 41-2013/CNB-INDECOPI. Aprueban cuatro Normas Técnicas Peruanas sobre conservas de productos pesqueros, anchoas y trucha. Diario El Peruano, XXX(12513): 498777-498778.

https://busquedas.elperuano.pe/download/url/apruebancuatro-normas-tecnicas-peruanas-sobre-conservas-deresolucion-n-41-2013cnb-indecopi-958159-3.

Kim J., Enache E. \& Hayman M. 2015. Halophilic and Osmophilic Microorganisms (Chapter 17). In: Salfinger Y. \& Tortorello M.L. (Eds) Compendium of Methods for the Microbiological Examination of Foods. American Public Health Association. DOI: 10.2105/MBEF.0222.022.

Liu W. \& Yang S.S. 2014. Oceanobacillus aidingensis sp. nov., a moderately halophilic bacterium. Antonie van Leeuwenhoek, 105: 801-808. DOI: $10.1007 / \mathrm{s} 10482-014-0128-1$.

MAGRAMA (Ministerio de Agricultura Alimentación y Medio Ambiente). 2017. El Mercado de la anchoa. Madrid, España.
Onyango L.A. \& Alreshidi M.M. 2018. Adaptive Metabolism in Staphylococci: Survival and Persistence in Environmental and Clinical Settings. Journal of Pathogens, 2018: 1092632. DOI:10.1155/2018/1092632.

Perez S., Czerner M., Patat M.L., Zaritzky N.E., Murialdo S.E. \& Yeannes M.I. 2018. Monitoring the characteristics of cultivable halophilic microbial community during salted-ripened anchovy (Engraulis anchoita) production. International Journal of Food Microbiology, 286(2): 179189. DOI: 10.1016/j.ijfoodmicro.2018.08.013.

Perez S., Murialdo S.E., Ameztoy I.M., Zaritzky N.E. \& Yeannes M.I. 2020. New insights into halophilic prokaryotes isolated from salting-ripening anchovies (Engraulis anchoita) process focused on histaminedegrading strains. Extremophiles, 24(5): 787-796. DOI: 10.1007/s00792-020-01194-w.

Puig Y., Leyva V., Aportela N., Camejo A. \& Tejedor R. 2019. Resistencia antimicrobiana en bacterias aisladas de pescados y mariscos. Revista Habanera de Ciencias Médicas, 18(3): 500-512.

http://www.revhabanera.sld.cu/index.php/rhab/article/vi ew/2440.

Pons-Sánchez-Cascado S., Vidal-Carou M.C., Mariné-Font A. \& Veciana-Nogués T. 2005. Influence of the freshness grade of raw fish on the formation of volatile and biogenic amines during the manufacture and storage of vinegarmarinated anchovies. J. Agric. Food Chem., 53(22): 8586-8592. DOI: 10.1021/jf050867m.

Rani G.N., Budumuru R. \& Bandaru N.R. 2017. Antimicrobial Activity of Honey with Special Reference to Methicillin Resistant Staphylococcus aureus (MRSA) and Methicillin Sensitive Staphylococcus aureus (MSSA). J. Clin. Diagn. Res., 11(8): DC05-DC08. DOI: $10.7860 / J C D R / 2017 / 30085.10347$.

Romanenko L.A., Lysenko A.M., Rohde M., Mikhailov V.V. \& Stackebrandt E. 2004. Psychrobacter maritimus sp. nov. and Psychrobacter arenosus sp. nov., isolated from coastal sea ice and sediments of the Sea of Japan. International Journal of Systematic and Evolutionary Microbiology, 54(5): 1741-1745.

DOI: 10.1099/ijs.0.63096-0.

SANIPES. 2016. Resolución de Dirección Ejecutiva $N^{\circ} 057$ 2016-SANIPES-DE. Aprueban Manual "Indicadores Sanitarios y de Inocuidad para los Productos Pesqueros y Acuícolas para Mercado Nacional y de Exportación". Diario El Peruano, XXXIII(13719): 590926-590927. http://www.sanipes.gob.pe/normativas/15_R_DE_N_05 7_2016_A1.pdf.

https://busquedas.elperuano.pe/normaslegales/apruebanmanual-indicadores-sanitarios-y-de-inocuidad-pararesolucion-no-057-2016-sanipes-de-1396873-1/.

Tanasupawat S., Chamroensaksri N., Kudo T. \& Itoh T. 2010. Identification of moderately halophilic bacteria from Thai fermented fish (pla-ra) and proposal of Virgibacillus siamensis sp. nov. J. Gen. Appl. Microbiol., 56: 369-379. DOI: 10.2323/jgam.56.369.

The Editorial Board (of Bergey's Manual). 2015. Sporosarcina. In: Whitman W.B., Dedysh S., DeVos P., Hedlund B., Kämpfer P., Rainey F.A., Trujillo M.E., Bowman J.P., Brown D.R., Glöckner F.O., Oren A., Paster B.J., Wade W. Ward N., Busse H. \& Reysenbach A. (The Editorial Board) Bergey's Manual of Systematics of Archaea and Bacteria. John Wiley \& Sons. Hoboken / New Jersey. DOI: 10.1002/9781118960608.gbm00563. 
Verdos G.I., Makrigiannis A., Tsigaras E. \& Boziaris I.S. 2018. Survival of food-borne bacterial pathogens in traditional Mediterranean anchovy products. J. Food Saf., 39: e12576. DOI: https://doi.org/10.1111/jfs.12576.

Yi-Guang C., Xiao-Long C., Wen-Jun L., Li-Hua X., MengLiang W., Qian P. \& Cheng-Lin J. 2008. Salinicoccus salitudinis sp. nov., a new moderately halophilic bacterium isolated from a saline soil sample. Extremophiles. 12: 197-203.

DOI: $10.1007 / \mathrm{s} 00792-007-0116-8$.
Zugarramurdi A., Parín M.A., Gadaleta L., Carrizo G. \& Lupin H.M. 2004. The effect of improving raw material quality on product quality and operating costs: a comparative study for lean and fatty fish. Food Control, 15(7): 503-509. DOI: 10.1016/j.foodcont.2003.08.001. 
Tabla 2. Caracterización de las bacterias halotolerantes aisladas del proceso de salado-madurado de anchovetas provenientes de Chimbote / Perú.

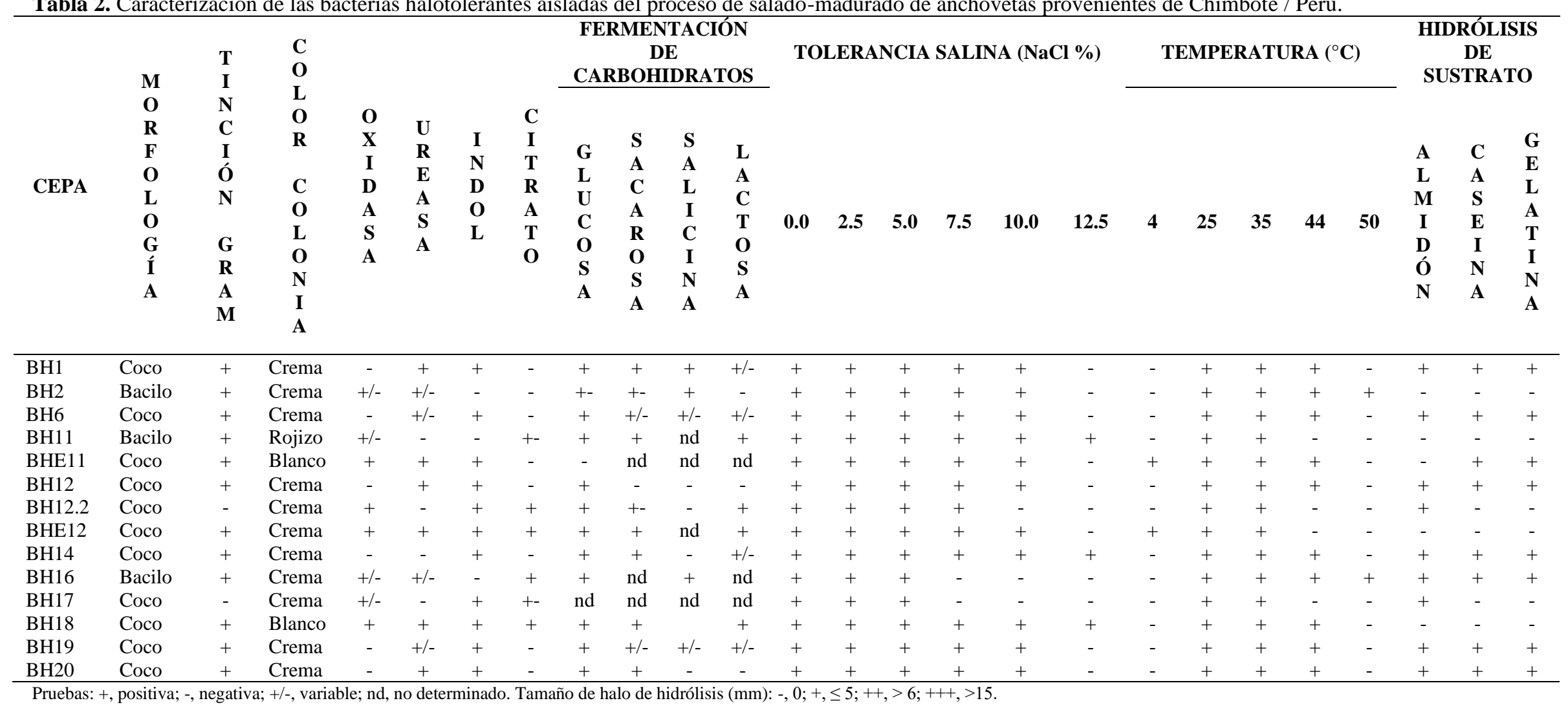

${ }^{1}$ Laboratorio de Microbiología / Dirección de Investigación, desarrollo, innovación y transferencia tecnológica / Instituto Tecnológico de la Producción. Carretera a Ventanilla Km 5.2, Callao, Perú.

2 rcespedes@itp.gob.pe.

${ }^{3}$ Laboratorio de Biología Molecular / Facultad de Farmacia y Bioquímica / Universidad Nacional Mayor de San Marcos. Jr. Puno 1002, Lima 1- Perú.

${ }^{4}$ susana.calderon2@unmsm.edu.pe. 